\title{
THE EFFECT OF SUBLETHAL CONCENTRATION OF LEAD ON DELTA-AMINOLEVULINIC ACID DEHYDRATASE ACTIVITY AND HEMATOLOGICAL PARAMETERS IN THE JAVANESE CARP Puntius gonionotus (BLEEKER)
}

\author{
Patimah, I.*) and S. Alias $\left.{ }^{*}\right)$
}

\begin{abstract}
The activity of the erythrocyte delta-Aminolevulinic acid dehydratase (ALA-D) of carp, Puntius gonionotus, was measured under a variety of lead $(\mathrm{Pb})$ exposure conditions. A four-week exposure of carp to $\mathrm{Pb}$ concentrations of $10 \mathrm{ppb}-300 \mathrm{ppb}$ strongly inhibited their ALA-D activities with increasing $\mathrm{Pb}$ concentrations. When carp were exposed to $\mathrm{Pb}$ concentration of $300 \mathrm{ppb}$, depressed activity of ALA-D became visible after only 2 days, and this activity declined further with increasing exposure of seven weeks in $\mathrm{Pb}$-free water. These characteristics indicate that this enzyme can be useful as a short-term indicator of $\mathrm{Pb}$ pollution. In the hematological work it was found that when the fish were exposed for 4 weeks to the highest $\mathrm{Pb}$ concentration $(300 \mathrm{ppb})$, they suffered from anaemia, with decreasing Hematocrit values. There was no significant $(\mathrm{P}>0.05)$ interaction between $\mathrm{Pb}$ concentration and either lactate level or blood glucose.
\end{abstract}

KEYWORDS: Lactate, glucose, Delta Aminolevulinic Acid (ALA-D), lead, sublethal.

\section{IN'TRODUC'TION}

The contamination of natural waters by lead $(\mathrm{Pb})$ is mostly caused by a variety of anthropogenic activities related to an increase in mining operations and industrial uses of this metal. Of the five most common and toxic heavy metals in the atmosphere (lead, mercury, cadmium, arsenic and selenium), $\mathrm{Pb}$ contributes $87.4 \%$ of the total atmospheric emissions from both anthropogenic and natural sources. The metal itself is used in many ways in sheet, foil or pipe forms. Alloys with antimony and/or tin are used for bearings, printing type, accumulator plates, solder, bullets and shot. White lead $(\mathrm{PbO})$ and lead carbonate $\left(\mathrm{PbCO}_{3}\right)$ are used in pottery glazing, and red lead $\left(\mathrm{Pb}_{3} \mathrm{O}_{4}\right)$ is a protective primer for steel. Most of the $\mathrm{Pb}$ in the atmosphere is from the consumption of leaded gasoline (Nriagu \& Pacyna, 1988), in which the organic compound, lead tetraethyl, is an "anti-knock" agent added to high octane petroleum. It is converted into a fine particulate inorganic form of $\mathrm{Pb}$ during combustion and discharged into the atmosphere.

Adverse effects caused by $\mathrm{Pb}$ poisoning in fishes have been reported with reference to both hematological and biochemical variables (Jackim, 1979; Hodson, 1976). Among the clinical symptoms described in fishes are anaemia, basophilic stippling of erythrocytes, muscular atrophy, the degeneration of the caudal fin and lordoscoliosis (Dawson, 1935).

Water quality criteria for heavy metals are often based on the response of fish to long-term metal exposures. However, studies of these responses may take several years and provide information on only one metal and one species of fish in one situation. A short-term indicator

*) Faculty of Fisheries and Marine Science, Universiti Pertanian Malaysia, 43400 UPM, Serdang, Selangor, Malaysia 
of sublethal $\mathrm{Pb}$ toxicity would provide a faster, more economical way of extending these results to other fish or other situations.

In blood, $\mathrm{Pb}$ is mainly (90\%) bound to erythrocytes (Lauwerys \& Hoet, 1993), so whole blood should be taken for analysis. Biological tests have been proposed for the detection of excessive exposure to $\mathrm{Pb}$, mainly based on the interference of $\mathrm{Pb}$ with several enzymatically controlled stages of the heme synthesis pathway. In vitro, $\mathrm{Pb}$ can inhibit the enzyme, (-Aminolevulinic acid synthetase, but in vivo it seems that an induction of the activity of this enzyme is more likely to be produced (Meredith et al., 1978). This action could result from a depression of the enzyme synthesis due to the decreased amount of heme. In fish, the sensitivity of delta ALA-D to lead poisoning had been demonstrated through three features: as a reduction of the ALA-D activity in liver and kidney of winter flounder, Pseudopleuronectes americanus and mummichog, Fundulus heteroclitus (Jackim, 1979); as depressed activity of red blood cell ALA-D in rainbow trout, Salmo gairdneri; brook trout, Salvelinus fontinalis; goldfish, Carassius auratus; and pumpkinseed, Lepomis gibbosus (Hodson, 1976); and in the erythrocytes, spleen, and renal tissue of rainbow trout, Salmo gairdneri (JohanssonSjÜbeck \& Larsson, 1979). Furthermore, the absence of erythrocyte ALA-D inhibition in fish exposed to cadmium, copper, zinc and mercury, indicated that this enzyme is quite specifically inhibited by $\mathrm{Pb}$ (Rodrigues et al., 1989).

In this work, the activity of (-Aminolevulinic acid dehydratase in the blood of $\mathrm{Pb}$ exposed and unexposed fish will be measured to determine whether this is a useful technique for quick identification of harmful $\mathrm{Pb}$ exposures.

\section{MATERIALS AND METHODS}

\section{Test Fish}

The fish, Javanese carp (Puntius gonionotus Bleeker), were obtained from the hatchery unit of Universiti Pertanian Malaysia, Serdang Selangor. They measured $20.0 \pm 0.90 \mathrm{~cm}$ in total length and $28.0 \pm 0.57 \mathrm{~g}$ in weight. They were acclimatized for 10 days before starting the experiment. The fish were fed once a day with a commercial diet, and the holding tanks were cleaned daily shortly after feeding.

\section{Test Water}

Lead nitrate (reagent grade) was dissolved in $0.1 \mathrm{~N}$ nitric acid solution, and a stock solution of $10 \mathrm{mg} / \mathrm{mL}$ (as $\mathrm{Pb}$ ) was made. The stock solution was diluted with seasoned water, and different concentrations of $\mathrm{Pb}$ for three types of exposure tests were prepared.

\section{Basic Method for Exposure Tests}

The test tanks were quadrangular aquaria $\left(150 \times 30 \times 30 \mathrm{~cm}^{3}\right)$, made of glass and subdivided into small interconnected cells $\left(30 \times 30 \times 21 \mathrm{~cm}^{3}\right)$ by a plastic net, to let water pass freely through all cells. The basic exposure test was conducted by circulation of test waters through test tanks by aeration and replacement of test waters at 48 hour intervals. The test was conducted at room temperature $\left(26-29^{\circ} \mathrm{C}\right)$. The fish were fed to satiation with commercial diet 5 hours prior to the replacement of the test waters. The $\mathrm{pH}$ of the test waters was within the range of 7.0-8.0 throughout the test period. Dissolved $\mathrm{Pb}$ from the test tanks was analysed for the actual concentration using an atomic absorption spectrophotometer (AAS-Model Shimadzu-670).

\section{Exposure Test-1}

In order to examine the relationships between ALA-D activity and water $\mathrm{Pb}$ concentration, water $\mathrm{Pb}$ concentration and blood $\mathrm{Pb}$ concentration, fish were exposed for 4 weeks to $\mathrm{Pb}$ concentrations of 10,75 and $300 \mathrm{ppb}$. A control was provided which had no $\mathrm{Pb}$ content. 
The experiment was carried out in the four different test tanks (as mentioned earlier) each containing 50 litres of test solutions where 1 fish was placed in each subdivision of the tank. The experiment was done in duplicate and repeated twice.

\section{Exposure Test - 2}

Fish were exposed for 4 weeks to water of $\mathrm{Pb}$ concentration of $300 \mathrm{ppb}$ and a control (no Pb). The test began with two test tanks per each of control water and $\mathrm{Pb}$ contaminated water exposed groups. One fish from each of the test tanks of each group was randomly collected for blood sampling. The remaining fish were redistributed randomly to each subdivision of the test tanks. Subsequently, the above procedure was repeated for every blood sampling.

\section{Exposure Test - 3}

To examine recoveries of ALA-D activities and $\mathrm{Pb}$ concentrations in the blood of fish, experimental fish were transferred to $\mathrm{Pb}$-free water and kept for 7 weeks after the fish had been exposed for 4 weeks to water $\mathrm{Pb}$ concentration of $300 \mathrm{ppb}$. The exposure test began with two test tanks each containing 5 subdivision per each group of control - water and $\mathrm{Pb}$ contaminated water exposed groups. After 7 weeks, fish from each of the test tanks of each group was randomly collected for blood sampling.

\section{Collection of Blood}

Each fish was anesthetized by immersion in tricaine methanesulfonate (MS-222) for several minutes before blood and tissue samples were collected. Blood was drawn by caudal peduncle puncture using a heparinized $3-\mathrm{ml}$ syringe equipped with a 20 - gauge needle and each fish was then weighed and measured. The blood was dispensed from the syringe into a heparinized test tube and measurement of Hematocrit (Ht), ALA-D activity and $\mathrm{Pb}$ concentrations were made.

\section{Measurement of ALA-D Activity}

Blood was assayed for ALA-D activity by a method modified from Granick et al. (1973). Two samples of $75 \mu \mathrm{L}$ of blood were drawn by caudal peduncal puncture using a chilled, heparinized capillary tube. One tube was capped and centrifuged to measure the micro-Hematocrit. Blood from the second tube was immediately transferred to parafilm and $20 \mu \mathrm{L}$ aliquots were added to each of three disposable centrifuge tubes at room temperature. The first was a blank which contained $100 \mu \mathrm{L}$ of $0.2 \%$ Triton $\mathrm{X}-100$ in $0.1 \mathrm{M}, \mathrm{pH} 6.2$ phosphate buffer. The second and the third tubes were duplicated tests and contained 100 $\mu \mathrm{L}$ of $0.2 \%$ Triton $\mathrm{X}-100$ and $670 \mu \mathrm{g} / \mathrm{mL}$ of Aminolevulinic acid in $0.1 \mathrm{M}, \mathrm{pH} 6.2$ phosphate buffer. The tubes were capped and the sample mixed and incubated at $37^{\circ} \mathrm{C}$ for 1 hour. The reaction was stopped with $300 \mu \mathrm{L}$ of an aqueous solution of $4.0 \mathrm{~g}$ of trichloroacetic acid and $2.7 \mathrm{~g}$ of mercuric chloride per $100 \mathrm{~mL}$. Each tube was centrifuged at $2500 \mathrm{~g}$ for 5 minutes and $350 \mu \mathrm{L}$ of supernatant was transferred to a glass test tube. The amount of porphobilinogen produced in the reaction was measured by adding $300 \mu \mathrm{L}$ of modified Ehrlich's Reagent to each test tube. This reagent consisted of $168 \mathrm{~mL}$ glacial acetic acid; $40 \mathrm{~mL}$ of $70 \%$ perchloric acid, $4.0 \mathrm{~g}$ of $\mathrm{p}$-dimethyl amino benzaldehyde, $0.7 \mathrm{~g}$ mercuric chloride, and $12 \mathrm{~mL}$ distilled water. The reagent was prepared fresh every time. After 15 minutes of color development, absorbance of each test solution was read against the appropriate blank at $553 \mathrm{~nm}$ using a spectrophotometer. The ALA-D activity was expressed as units per milliliter of red blood cells per hour using the formula:

$$
\text { Activity }=\frac{D \times A}{T \times H}
$$

where: $\mathrm{D}=$ dilution coefficient $=50$

$\mathrm{A}=$ absorbance after 1 hour

$\mathrm{T}$ = incubation time ( 1 hour)

$\mathrm{H}=$ hematocrit $\div 100$ 


\section{Lead Analysis}

$200 \mu \mathrm{L}$ of nitric acid $(61 \%)$ and $200 \mu \mathrm{L}$ of hydrogen peroxide were added to $200 \mu \mathrm{L}$ of collected blood. The mixture was wet - digested on the hot plate at about $140^{\circ} \mathrm{C}$ until dried. The dried digestate was dissolved with $4 \mathrm{~mL}$ of $0.1 \mathrm{~N}$ nitric acid solution. Water $\mathrm{Pb}$ concentrations were determined by adding $0.8 \mathrm{~mL}$ of concentrated nitric acid to $100 \mathrm{~mL}$ of each test water and the test waters were stored at room temperature until analysis. The relationships between blood and water $\mathrm{Pb}$ were determined using statistical analysis and $\mathrm{Pb}$ concentrations were determined using Atomic Absorption Spectrometry (Model Shimadzu-670).

\section{Hematological Parameters Analysis}

Blood samples were taken within 35 seconds after collecting the fish from the tank. Hematocrit $(\mathrm{Ht})$ was measured using capillary tubes filled with blood and centrifuged at $11000 \mathrm{r} / \mathrm{min}$ for 6 minutes. Hemoglobin, glucose and lactase levels were measured based on calorimetric determinations using Sigma Diagnostics Commercial Kits.

\section{i) Total Hemoglobin Analysis}

The total hemoglobin analysis was determined by adding $5.0 \mathrm{~mL}$ Drabkin's Solution to the blank and test samples. To each of the samples, $20 \mu \mathrm{L}$ whole blood was added and allowed to stand for 15 minutes at room temperature $\left(26^{\circ} \mathrm{C}\right)$. The absorbance was read at a wavelength $540 \mathrm{~nm}$. Total hemoglobin concentration $(\mathrm{g} / 100 \mathrm{~mL})$, was determined using the calibration curve.

\section{ii) Glucose Analysis}

For the glucose analysis, all test tubes were labelled as either BLANK, STANDARD or TEST. The blank test tube had $0.1 \mathrm{~mL}$ distilled water added and the STANDARD had $0.1 \mathrm{~mL}$ Glucose Standard Solution Catalogue No.
635-100 added. The TEST tubes had $0.1 \mathrm{~mL}$ plasma, then $5.0 \mathrm{~mL}$ O-Toulidine Reagent, Catalogue No. 635-6 added. It was mixed by lateral shaking. After shaking, all tubes were placed in a vigorously boiling water bath for exactly 10 minutes. All tubes were quickly removed and cooled to room temperature by placing in tap water for approximately $3 \mathrm{~min}$ utes. The contents of the tubes were then transferred to cuvets, and the absorbance of STANDARD and TEST at $635 \pm 15 \mathrm{~nm}$ were recorded using the blank as reference. All reading were completed within 30 minutes. Glucose concentrations were calculated using the formula;

$$
\text { Glucose }(\mathrm{mg} / \mathrm{mL})=\frac{\text { A Test }}{\text { A Standard }} \times 100
$$

\section{iii) Lactate Analysis}

Lactate Reagent Solution was used for this analysis. To each sample tube, $1.0 \mathrm{~mL}$ of Lactate Reagent Solution was added. To tubes labelled as STANDARD, $10 \mu \mathrm{L}$ of Lactate Reagent Solution, Catalogue No. 826-10 was added. $10 \mu \mathrm{L}$ of blood plasma was added to tubes labelled TEST. All tubes were incubated for 5 to 10 minutes. The absorbance (A) of STANDARD and TEST vs. BLANK as reference were recorded at $540 \mathrm{~nm}$. The reading was completed within 10 minutes following incubation. Lactate concentration was calculated using the following formula:

$$
\text { Lactate }(\mathrm{mg} / 100 \mathrm{~mL})=(40.5)(\mathrm{Au})(\mathrm{C})
$$

where: $\mathrm{Au}=$ Absorbance of unknown $\mathrm{C}=$ Calibration factor

\section{Data Analysis}

The data were analyzed for statistical significance between the controls and the Pb-exposed fish by the Student's t-test. Significant differences were establish at the 0.05 level. 


\section{RESULTS}

\section{Water Quality}

The quality of water in the holding tanks for the experiment was within the acceptable range for fish production as shown in Table 1.

Table 1. Ranges of the water quality in the holding tanks.

\begin{tabular}{llr}
\hline Parameter & & Holding tanks \\
\hline Dissolved oxygen & $(\mathrm{ppm})$ & $6.9-8.3$ \\
Temperature & $\left({ }^{\circ} \mathrm{C}\right)$ & $27.3-28.0$ \\
$\mathrm{pH}$ & & $7.1-7.8$ \\
Ammonium & $(\mathrm{ppm})$ & $0.48-0.3$ \\
Total hardness & $(\mathrm{ppm})$ & $53.4-55.7$ \\
\hline
\end{tabular}

\section{Lead Concentrations in the Exposure Tanks Water}

Actual $\mathrm{Pb}$ concentrations in the experimental tanks were found to be higher than the nominal concentrations. The deviations from the expected values were less if the background $\mathrm{Pb}$ in control water was subtracted. All the subsequent results were compared to actual concentrations. The determined $\mathrm{Pb}$ concentrations were the total $\mathrm{Pb}$ levels since the water samples were stored at $\mathrm{pH} 1$ with nitric acid until analysis. The $\mathrm{Pb}$ concentrations in the water (except for the control water) were found to have decreased after exposure periods of 48 hours, but the levels agreed well with the nominal levels. On the other hand, the $\mathrm{Pb}$ concentration of the control water tanks increased after exposure for 48 hours, but the cause of increasing level was unknown. Statistical significance between $\mathrm{Pb}$ concentrations at 0 and 48 hours using Student's t-test was not established at $5 \%$ level.

\section{ALA-D Activity}

After 4 weeks, the erythrocyte ALA-D activity in the $\mathrm{Pb}$-exposed fish showed a successive decrease (by $24 \%, 41 \%$, and $80 \%$, respectively) with the increased $\mathrm{Pb}$ concentration in the water (Figure 1). No obvious recovery of ALA-D activity was seen after the fish were transferred to clean water for 7 weeks.

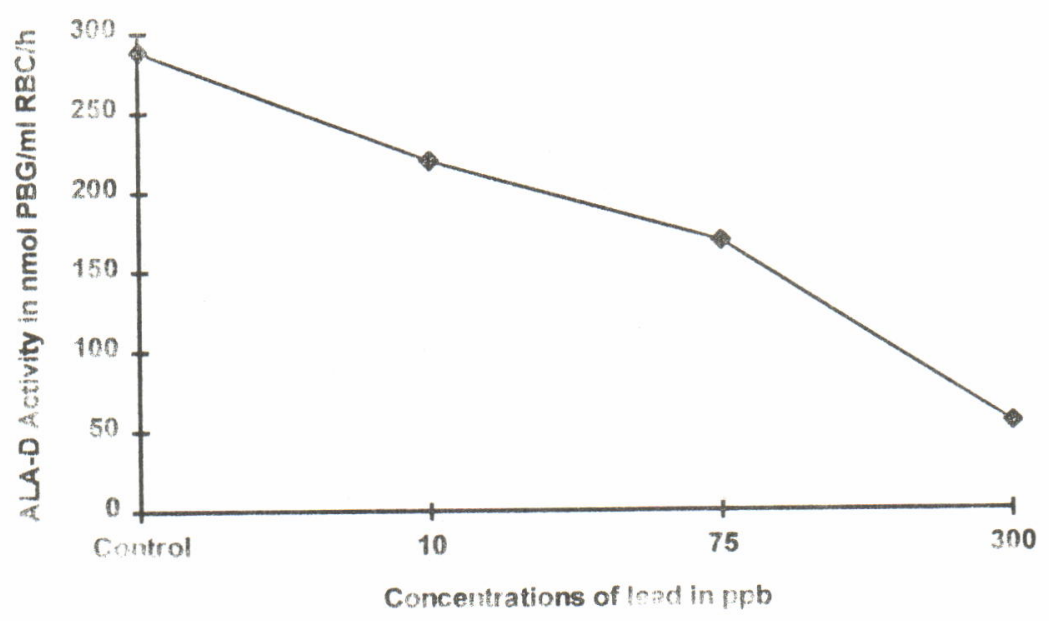

Figure 1. Variation in erythrocyte $\delta$-ALA-D activity of Puntius gonionotus after 4 weeks of exposure. 


\section{Blood Glucose and Lactate Levels}

Lead induced biochemical alterations included a hyperglycemic response at 4 weeks, when the blood glucose values for the highest $\mathrm{Pb}$ concentration exposure were $46.5 \%$ higher than the control values, but no significant differences was found between the other groups of 10 and $75 \mathrm{ppb}$ of lead concentrations. By contrast, a significant reduction occurred in the blood glucose level of Javanese carp exposed to $75 \mathrm{ppb}$ of $\mathrm{Pb}$.

On the other hand, no significant deviation in lactate level with any of the concentrations of toxicant was detected. The highest level of lactate after exposure to $\mathrm{Pb}$ was found to be $57.06 \mathrm{mg} / 100 \mathrm{~mL}$ and for the lowest level of lactate was $35.76 \mathrm{mg} / 100 \mathrm{~mL}$, (Figure 2).

\section{Total Hemoglobin}

After 4 weeks, fish exposed to 10, 75 and 300 ppb showed no significant deviations from the control group. Fish exposed to $300 \mathrm{ppb}$ showed reduced values of hemoglobin to $9.6 \pm 0.04 \mathrm{~g} /$ $100 \mathrm{~mL}$ compared to a control group of $12.6 \pm$ $0.04 \mathrm{~g} / 100 \mathrm{~mL}$ (Figure 3).

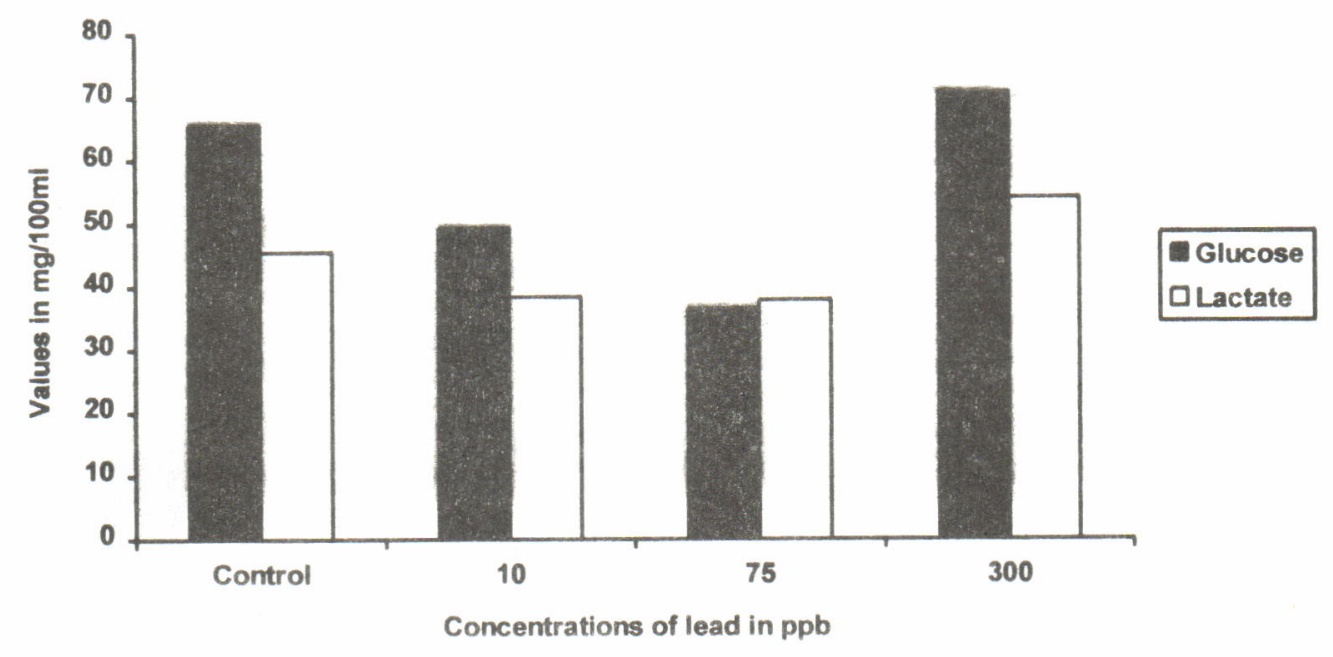

Figure 2. Blood glucose and lactate levels after 4 weeks of exposure of fish to different lead concentrations.

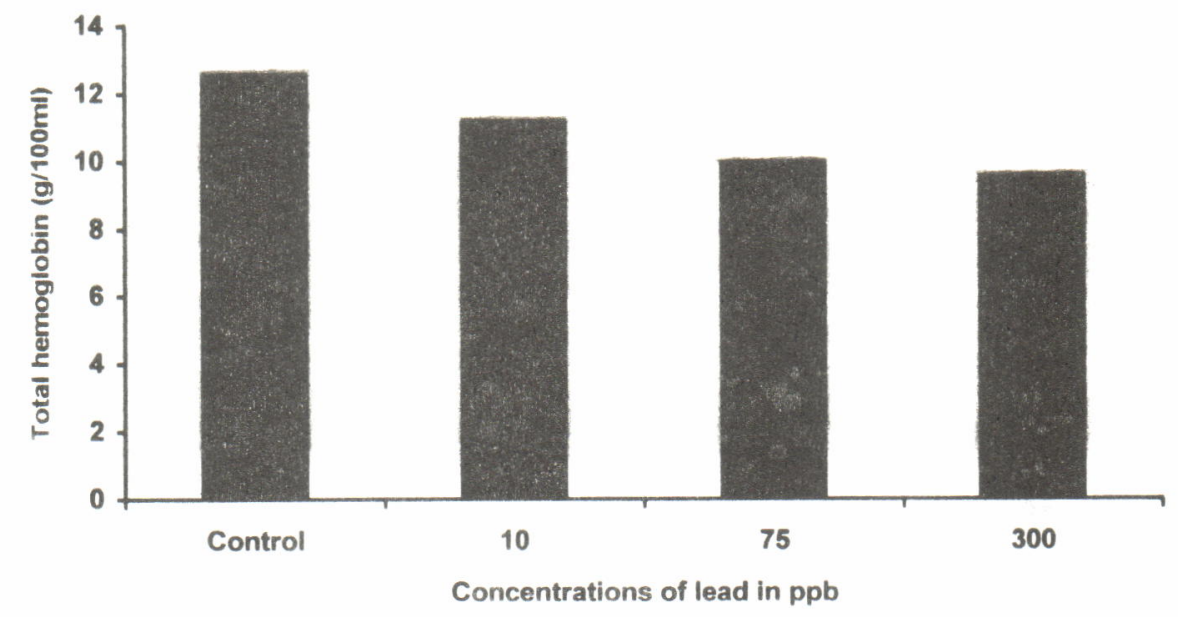

Figure 3. Hemoglobin levels after 4 weeks of exposure of fish to different lead concentrations 


\section{DISCUSSION}

The results show that the ALA-D activity in the erythrocytes is strongly inhibited by inorganic $\mathrm{Pb}$ and that the degree of this inhibition increases with increased $\mathrm{Pb}$ concentration in the water. An inhibitory action of $\mathrm{Pb}$ on the erythrocyte ALA-D is well documented for various vertebrates including man (Botts, 1977). The primary mechanism behind this inhibition seems to be that essential sulphydryl groups in ALA-D are inactivated by $\mathrm{Pb}$ (Gibson and Goldberg, 1970, Granick et al., 1973).

In $\mathrm{Pb}$-exposed mammals, the erythrocytes ALA-D activity shows a good negative correlation to the concentration of $\mathrm{Pb}$ in blood (Hernberg et al., 1970). A similar correlation is apparently valid also for fish exposed to $\mathrm{Pb}$ (Hodson et al., 1977; Nakagawa et al., 1995). The last mentioned study also revealed a negative correlation between the erythrocytes' ALA-D activity and the logarithm of $\mathrm{Pb}$ concentration in the water. In the present study, it was shown that erythrocyte ALA-D activities of Javanese carp were depressed with increasing $\mathrm{Pb}$ concentration in water after exposure to $\mathrm{Pb}$ concentrations of 10,75 and $300 \mathrm{ppb}$. The degree of enzyme inhibition induced by $\mathrm{Pb}$ in various nominal concentrations in the present study. This agrees well with the results obtained by Hodson et al. (1977) and Nakagawa et al. (1995), that ALA-D in fish blood is a parameter that reflects the degree of $\mathrm{Pb}$ concentration.

After 4 weeks of exposure, there was a positive correlation between blood lead concentrations and water concentrations. A similar result was reported for common carp (Nakagawa et al., 1995). Blood lead concentrations in Javanese carp exposed to $\mathrm{Pb}$ concentration of $300 \mathrm{ppb}$ did not reach equilibrium, but continued to increase throughout 4 weeks of exposure. Blood lead concentration also reflected the degree of $\mathrm{Pb}$ contamination of fish. Moreover it was found that there is a clear negative correlation between blood lead concentrations and ALA-D activities in Javanese carp. Similar results were observed in the exposed test using rainbow trout and brook trout (Hodson et al., 1977), common carp (Nakagawa et al., 1995) and the field survey of longear sunfish, Lepomis megalotis (Dwyer et al., 1988). Because ALA-D activity is inversely related to blood $\mathrm{Pb}$, which in turn reflects the degree of $\mathrm{Pb}$ contamination of the fish, Hodson et al. (1977) reported the blood ALA-D is also useful for diagnosing past exposure to $\mathrm{Pb}$, even if $\mathrm{Pb}$ in the water at the time of analysis is of the usual background concentration.

No significant recovery of the ALA-D activity in erythrocytes was seen after transfer of the $\mathrm{Pb}$-exposed fish to clean water for 7 weeks. This differs from previous findings by Hodson et al. (1977) on rainbow trout and Nakagawa et al. (1995) using common carp, exposed to $\mathrm{Pb}$ in freshwater is inconsistent might be explained by the shorter exposure period ( 2 weeks) in the latter studies compared to the present (4 weeks).

It is obvious from the present results that the periods of 7 weeks stay in $\mathrm{Pb}$-free water is not sufficient for the erythrocyte ALA-D activity to return to normal levels. This slow recovery makes this enzyme useful as a diagnostic indicator for detecting $\mathrm{Pb}$ exposure fish, even in water, where the $\mathrm{Pb}$ content has returned to background levels. The present finding on the erythrocyte ALA-D also supports the opinion of Hodson (1976) and Hodson et al. (1977) that determination of ALA-D activity provides a sensitive and fast technique for determination of sublethal disturbances induced by $\mathrm{Pb}$. The test can therefore be used for the estimation of $\mathrm{Pb}$ exposure of fish and hence, $\mathrm{Pb}$ in water. The measurement of this enzyme seems to be much easier for detecting $\mathrm{Pb}$ poisoning than the determination of $\mathrm{Pb}$ in water or in blood and other tissues (Morgan \& Burch, 1972).

With the highest $\mathrm{Pb}$ concentration (300ppb), a hyperglycemic response was induced when blood glucose value was $46.5 \%$ higher than the control value. Similar results were observed with the blood lactate level (24\%). Glucose and lactate increases are usual responses after 
stress action (Soivio \& Oikari, 1976), although in some cases, a decrease in glucose level may be due to disturbances on energetic pathways. Such a response has been detected in rainbow trout, Salmo gairdneri after exposed to 10,75 and $300 \mathrm{ppb} \mathrm{Pb}$ for 4 weeks (Haux et al., 1986). Glucose is released by corticosteroids whose elevation has been described as a primary response to most stressors, including heavy metals (Donaldson, 1981). Lactate elevation could be related to anaerobic motabolism. which could be partially due to hypoxia generated by motal accumulation on the gills (Skidmope, 1970)

There was a slight decrease in bhed hemoglobin concentration when exposed to the highest $\mathrm{Pb}$ concentrations, but still no significant deviations from the control group. In the present work, the decreased Hematocrit value after exposure to $\mathrm{Pb}$ contamination was indicative of a severe anaemic state causally related to prolonged $\mathrm{Pb}$ exposure. While the anaemia was evident only in fish exposed to the highest $\mathrm{Pb}$ concentration, the inhibition of erythrocyte ALA-D activity was apparent even in fish exposed to the two lower concentrations. Probably, the anaemia is largely a result of a disturbed hemoglobin synthesis due to the observed blocking effect of $\mathrm{Pb}$ on ALA-D. Other contributing action mechanisms are, however, possible. In mammals, it has been shown that the red cell survival time is shortened by $\mathrm{Pb}$ (Hernberg, 1976). The mechanisms by which $\mathrm{Pb}$ causes this effect are not fully understood, but changes such as increased osmotic resistance and increased mechanical fragility of the red blood cells are certainly involved (Waldron, 1966).

\section{CONCIUUSION}

It can be concluded that $\mathrm{Pb}$ exposure causes a strong inhibition on enzyme ALA-D in fish, and that this effect probably contributes to the anaemic condition observed in fish exposed to the highest $\mathrm{Pb}$ concentration. The $\mathrm{Pb}$-exposed fish showed a dose-dependant inhibition of erythrocyte ALA-D activity. The slow recovery of the ALA-D activity makes this enzyme useful as diagnostic indicator for detecting $\mathrm{Pb}$ exposure of fish, even several weeks after the exposure has ceased.

Despite the persistent, pronounced inhibition of ALA-D activity in the Pb-exposed fish, no significant effects could be detected on the hemoglobin content and Hematocrit values. Thus the consequence of the $\mathrm{Pb}$-induced enzyme inhibition, in terms of erythrocyte function, is still an unanswered question.

Thus, similar to the situation in the highest vertebrates, the inhibition of ALA-D secms to be sensitive (perhaps the carliest) measurable effect of $\mathrm{Pb}$ exposure in fish. It is however difficult to evaluate the significance with respect to animal health, as most of the enzymes have a relatively large reserve capacity even in mammals (Hernberg, 1976). Further experiments are needed to elucidate the long-run consequences of the observed ALA-D inhibition on erythrocytes' function and ultimately on the well-being of the fish. Furthermore, the persistence of the enzyme inhibition must be a subject for further studies.

The $\mathrm{Pb}$ exposure also affected the carbohydrate metabolism. A persistent hypoglycemia and an initial slight increase in blood lactate were found after $\mathrm{Pb}$ exposure. The hypoglycemic response might be a result of $\mathrm{Pb}$-induced morphological and functional changes in renal tubular cells. Such a renal effect is common in $\mathrm{Pb}$-exposed mammals and is accompanied by glucosuria.

\section{REFERENCES}

Botts, R. P. 1977. The short term effects of $\mathrm{Pb}$ on domestic and wild animals. EPA report: EPA 600/3-77-900, Washington, D.C. 
Dawson, A.B. 1935. The hemopoietic response in the catfish, Ameiurus nebulosus to chronic $\mathrm{Pb}$ poisoning. Biology Bulletin. 68 : 335-346

Donaldson, E. M. 1981. The pituitary - interrenal axis as an indicator of stress on fish. p. 11-47. In: Stress and Fish. A.D. Pickering (ed.). Academic Press, London.

Dwyer, F.J., C.J. Schmitt, S.E. Finger, and R.M. Mehcle. 1988. Biochemical changes in longear sunfish, Lepomis megalotis, associated with $\mathrm{Pb}$, cadmium, and zinc from mine tailings. Journal of Fish Biology. $33: 307-317$

Gibson, S.L.M. and A. Goldberg. 1970. Defects in haem synthesis in mammalian tissues in experimental $\mathrm{Pb}$ poisoning and experimental porphyria. Clinical Science. $38: 63$

Granick, J.L., S. Sassa, S. Granick, R.D. Levere and A. Kappas. 1973. Studies in $\mathrm{Pb}$ poisoning II. Correlation between the ratio of activated to inactivated $\delta$ - aminolevulinic acid dehydratase activity of whole blood and the blood $\mathrm{Pb}$ level. Biochemistry Med. 8: 149-159

Haux, C., A. Larsson, G. Lithner and M.L. Sjšbeck. 1986. A field study of physiological effects on fish in $\mathrm{Pb}$-contaminated lakes. Environmental Toxicology and Chemical. $5: 283-288$

Hernberg, S., J. Nikkanen, G. Mellin and H. Lilius. 1970. $\delta$-aminolevulinic acid dehydratase activity as a measure of $\mathrm{Pb}$ exposure. Archives of Environmental Health. $21: 140-147$

Hernberg, S. 1976. Biochemical, subclinical and clinical responses to $\mathrm{Pb}$ and their relations to different exposure levels, as indicated by concentration of $\mathrm{Pb}$ in blood. p. 404 .In: Effects and dose response relationships to toxic metals. G. F. Nordberg (ed.). Amsterdam-Oxford-New York : Elsevier
Hodson, P.V. 1976. $\delta$-aminolevulinic acid dehydratase activity of fish blood as an indicator of a harmful exposure to Pb. Journal of Fish Research Board of Canada. $33: 268-271$

Hodson, P.V., B.R. Blunt, D.J. Spry, and K. Austen. 1977. Evaluation of erythrocyte $\delta$-aminolevulinic acid dehydratase activity as short term indicator in fish of a harmful exposure to $\mathrm{Pb}$. Journal of Fish Research Board of Canada. 34:501-508

Jackim, J.E. 1979. Influence of $\mathrm{Pb}$ and other metals on fish delta-aminolevulinic acid dehydratase activity. Journal of Fish Research Board of Canada. 30:560-562

Johansson-Sjšbeck, M.L. and A. Larsson. 1979. Effects of inorganic $\mathrm{Pb}$ on delta aminolevulinic acid dehydratase activity and hematological variables in the rainbow trout, Salmo gairdneri. Archives of Environmental Contamination and Toxicology. 18: 419-431

Lauwerys, R.R. and P. Hoet. 1993. Industrial Chemical Exposure: guidelines for biological monitoring, 2nd. ed. Lewis Publishers. Boca Raton, Florida. 318 p.

Meredith, P., M. Moore and B. Campbell. 1978. $\delta$ aminolevulinic acid metabolism in normal and $\mathrm{Pb}$ exposed humans. Toxicology.9: 1-7

Morgan, J. M., and H. B. Burch. 1972. Comparative tests for diagnosis of $\mathrm{Pb}$ poisoning. Archives of International Medicine. 130: 335

Nakagawa, H., K. Nakagawa and T. Sato. 1995. Evaluation of erythrocyte 5-aminolevulinic acid dehydratase activity in blood of Cyprinus carpio as an indicator in fish with water $\mathrm{Pb}$ pollution. Fisheries Sciences. 61 (1) : $91-95$

Nriagu, J.O and J.M. Pacyna. 1988. Quantitative assessment of worldwide contamination of air, 
water and soils by trace metals. Nature. 333: 132-139

Rodrigues, A.L., M.L. Bellinaso and T. Dick. 1989. Effects of some metal ions on blood and liver delta-aminolevulinate dehydratase of Pimelodus maculatus (Pisces, Pimelodidae). Comparative Biochemical and Physiology. 94B (1) : 65-69

Skidmore, J. F. 1970. Respiratory and osmoregula- tion in rainbow trout damage with zinc sulfate. Journal of Experimental Biology. 52: 481 - 494

Soivio, A. and A. Oikari, 1976. Hematological effects of stress on a teleost Exos lucius L. Journal of Fish Biology. 8: 397-411.

Waldron, H.A. 1966. The anemia of $\mathrm{Pb}$ poisoning : A review. Brit. J. Ind. Med. $23: 83$ 